\title{
Proposal For A New Pedagogical Approach In Teaching Anatomy To Medical Students, Part I: Fascia Continuity In The Anatomy Curriculum
}

Research Article

John Joseph Sharkey ${ }^{1 *}$, Karen Kirkness ${ }^{2}$

${ }^{1}$ Clinical Anatomist, Faculty of Medicine, Dentistry and Clinical Sciences, University of Chester/NTC, 15-16aSt Joseph's Parade, Dorset St, DO7 FR6C Dublin, Ireland.

${ }^{2}$ Hull York Medical School, Health Professions Education Unit (HPEU), University of York, Heslington, York, YO10 5DD, United Kingdom.

\section{Abstract}

\begin{abstract}
Medical students and post-graduate medical specialists, for example, physicians, surgeons, anaesthesiologists and gynaecologists require more than a simple impression of anatomy. A consensus exists that the study of anatomy by dissection provides the most realistic command of continuity, and embryological forming,essential for safe, effective clinical practice in medicine. Evidence demonstrates effective pedagogies are linked to teacher behaviour, level of teacher knowledge and understanding of anatomy. Importantly, a student's metacognition is significantly influenced by ateachers beliefs. For example, teaching an anatomy of 'parts,' without due attention to continuity, can compound a student's belief that the human body has discontinuous 'parts' therefore lackingthe "wholistic" continuity implicit in the tensegrity model of biologic form. Classically, anatomy has long been taught in continuity with embryology, physiology and histology, providing a robust academic foundation in the adjacency of form and function. This illustrates an existing recognition that the human body works as a wholistic entity and that any re-arrange mentor change can affect the global health of an individual. Medical anatomy teachers should, therefore, possess the pedagogical knowledge to support an accurate vision of a wholistic, unified body.
\end{abstract}

It should be recognised that the connective tissue fascia, and its ubiquitous nature, has, for decades been neglected and underappreciated in spite of the efforts of several prominent anatomists to draw attention to it. Surgeons in training need to be aware that knowledge of fascia anatomy allows for minimally disrupting connective tissue in one body region thereby significantly reducing risk of pain and loss of function in local or more anatomically distant regions. Teaching anatomy using classical methods of dissection and prosection does not have to remain an outdated exercise in cutting up tissue (anatomy, from 'temnein' to cut) for the express purpose of memorising parts. Through appreciating fascial continuities, dissection methods can and are undergoing modernisation through soft-fix technologies as well as tissue-sparing dissection methods. These pedagogic innovations are in double service to the study of anatomy, in that they encourage the wholistic view of the tensegral human form and its function. Such a view is considered to be more suited to a medical curriculum fit for the 21 st century.

Keywords: Pedagogy; Fascia; Anatomy; Medical Curriculum; Wholistic; Surgical; Tensegrity.

\section{Introduction}

Of anatomy departments surveyed, as part of a review concerning "the anatomy curriculum and who teaches it", 76\% of respondents reported inclusion of dissection in the first two years of their curriculum [1]. There is little disagreement among advanced medical students, and medical specialists, that anatomy knowledge is important for providing safe, effective medical knowledge and clinical practice [2]. There is also little argument concerning the importance of location specific anatomy and knowledge concerning anatomical detail of organs, for example, the liver [3].

What is clearly missing from the current medical anatomy curriculum is a description of the wholistic continuity of human form and an appreciation for the ubiquitous hierarchical nature of fascial tissue [4]. Fascia has been categorised in a functional manner

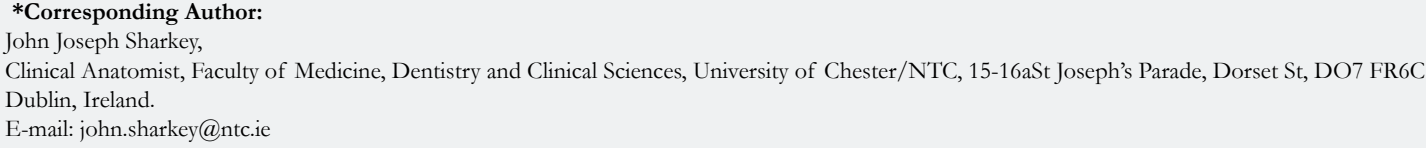

Citation: John Joseph Sharkey, Karen Kirkness. Proposal For A New Pedagogical Approach In Teaching Anatomy To Medical Students, Part I: Fascia Continuity In The Anatomy Curriculum. Int J Anat Appl Physiol. 2021;7(5):205-208. doi: http://dx.doi.org/10.19070/2572-7451-2100039

Copyright: John Joseph Sharkey ${ }^{\circ} 2021$. This is an open-access article distributed under the terms of the Creative Commons Attribution License, which permits unrestricted use, distribution and reproduction in any medium, provided the original author and source are credited. 
as follows:

Gliding, Restraining, Containing, Force Transductive, Communicative, Septal, Invaginating and Osseus[5] [Fig 1].

Knowledge concerning embryogenesis of fascia informs surgical approaches thus allowing for bloodless plains to be accessed, in turn, supporting minimally invasive surgery $[6,7]$. However, less than modest consideration is given to global implications of surgical disruption to fascia with the emphasis being placed exclusively on knowledge of local surgical anatomy [8].

While local anatomical knowledge is an essential pedagogic component, the lack of global considerations to disrupted, thickenedor rearranged (i.e. fibrotic)fascia is viewed as a flaw in appreciating fascial continuity [9]. In the medical curriculum the topic of fascia planes is discussed from an embryological point of view, with a specific focus on the spread of infections, but not on fascia continuity generally, however it is considered an essential element of the medical curriculum [see Figures 2 and 3] [10]. The use of so-called individual parts, or prosection pedagogy, has been seen as an effective resolution for many medical schools wishing to find a solution to the perceived plethora of issues surrounding body donation programs required for the provision of full-body cadaver dissection [11] especially since COVID.
Solving one such problem, utilising prosected specimens, risks compounding the notion of disconnected 'parts' and creates a new problem whereby medical students fail to appreciate the wholistic nature of the fascial body. Smith et al [12] highlighted opinions that expressed the need for medical students to attain a comprehensive body of 'fact based knowledge' with emphasis on clinical skills. From the pedagogical viewpoint, and specifically related to this review, it is interesting to note the explicit fact, expressed by Monkhouse and Farrell, that the structure of the human body, while individual and unique, has not changed [13]. Time wasting and lack of a cohesive structure, due to promotion of students personal curiosity and experiment, have been viewed as undesirable while an excellent knowledge of structure and function have been identified as essential [13]]. Indeed the anatomy of humans has not, and will not change. However, fascia has been, largely, left out and thus described as the Cinderella tissue reflecting the fact that medical anatomy has inadvertently failed to recognise the continuity of this body-wide net [14].

Fascia described as the "Cinderella tissue" expresses the implicit reality that, while human anatomy does not change, a change in the pedagogy of the medical curriculum is urgently warranted.It has been suggested that describing and appreciating fascia conti-

Figure 1. In this cadaveric specimen image muscle fiber is clearly evident, however, it becomes obvious that the most abundant tissue is fascia. The anatomist has already removed the skin and superficial fascia and reflected, superiorly and lateral, the pectoralis major to allow a clearer view of the ubiquitous nature of the thoracic fascia profunda investing, invaginating, penetrating, separating, connecting and continuous. Image: Sharkey, J 2019.

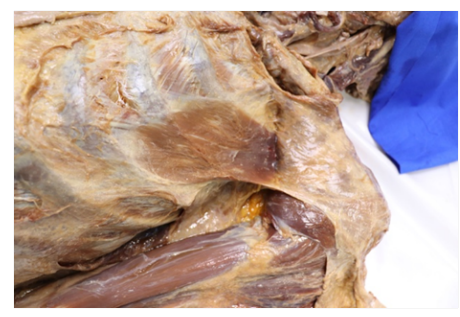

Figure 2. This image of a posterolateral view of thigh shows muscle fibers clearly invested in the fascia lata posterior to the more laterally positioned iliotibial thickening known as the iliotibial band. This continuity of muscle with its associated fascia allows for an explanation concerning the transfer of nutritious, or unhealthy, forces from one anatomical site to more distant sites in an omnidirectional fashion \{i.e., mechanotransduction]. Image: Sharkey, J. 2012.

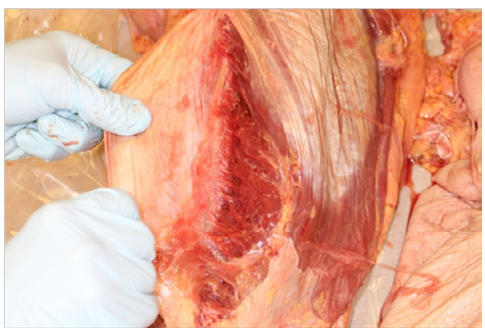

Figure 3. An image of the anti-brachial fascia demonstrating a continuous unbroken weave of fascial tissue from the more superior brachial fascia expressing densifications reflecting speciality including the tendon of the biceps brachii and the less dense Lacertus fibrosis. Appreciating the ubiquitous nature and unique morphology of site specific fascia on a global basis provides the student with a wholistic view of human form and function. Image: Sharkey, J. 2019.

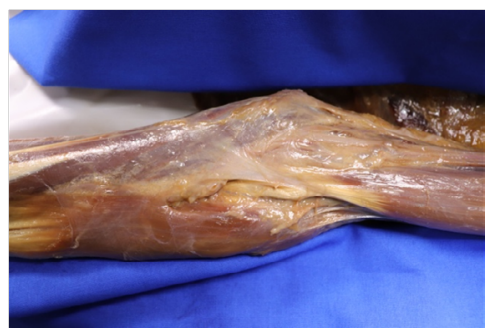


Figure 4. The icosahedron baby. Operating at multiple scales human structure is organised as nested tensegrities within tensegrities each operating with autonomy and also collectively from the nuclear level up, not limited to organ systems level. Image: Sharkey, J.

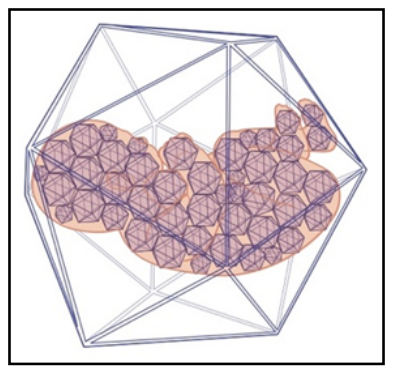

nuity would be in the best interest of medical students and would address the past failures to recognise the now established multiple roles of fascia in posture, pain science, pain referral, movement, surgical and clinical therapeutic interventions [4-6, 15-21]. Tubbs et al, point to a consensus concerning a core medical syllabus that, without containing unnecessary detail and rote learning, would support medical graduates becoming proficient in providing safe, effective clinical practice [8]. That said, an argument can be made for improving effectiveness and safety in medicine by including a description of "the ubiquitous universal singularity that is fascia"into a medical syllabus [21].

A 2009 study by Stecco et al explored the anatomical continuity of the muscles involved in flexion of the arm and forearm [4] while another informative study described the morphological characteristics and specific spatial disposition of fascia related to the muscles of pectoral girdle [22]. What both studies demonstrated clearly is the "spreading out" of fascial aponeurosis and fascial insertions to more distant omni directionally orientated anatomical locations. For example, while the gliding properties of the fascia was observed to change specific to its anatomical location and morphology a clear continuity was observed providing structural reinforcement of distant fascial structures with visual evidence of multidirectional routes of vectorial force to distant anatomical locations. These cadaveric observations provide a basis for the reasonable hypothesis that forces shared in an omnidirectional manner play a vital role in activation of numerous proprioceptive and interoceptive facilities [4, 23]. With confirmation concerning the contractile ability, rich innervation of free nerve endings, existence of newly discovered fasciacytes, and rich component of mechanoreceptors, it would seem fascia has emerged as the most important connective tissue within the human body [23-25]. Tensegrity as a concept was born in mid-20th-Century art and architecture, popularised through the work of Buckminster Fuller. Essentially, tensegrity describes a structure balanced through the qualities of its two co-creative forces, tension and compression [5]. Biologic architecture, from the tensegrity point of view, arises from the tensional network of filamentous tissues through cellular architecture autoregulating these forces in constant flux [5]. That the cellular (and extracellular) matrix are continuously adapting in response to mechanical forces is now well recognised. This leads to the following questions, why has the model of anatomy not been updated accordingly? Why is there such a stark disconnect between advances in our understanding of histology, biophysics, and cell biology?

Significant changes have occurred to the modern medical curriculum placing additional competitive time pressures on an already stressed syllabus leading to a reduction in time allocated to anatomy [26]. It should be possible to include fascia anatomy and science by integrating the topics within already existing curriculum modules. According to Harden a curriculum is not the syllabus alone. Harden claims the curriculum is a programme of study where, similar to the model of tensegrity, the whole is greater than the sum of its parts [27]. In an effort to keep up with the demands required of a modern day physician, and other medical specialists, modification of the current medical curriculum is required [28]. Organising fascia content in an integrative longitudinal axis approach, modified to fit across the current curriculumin continuity with the wider modular content, would give fascia the place it deserves within modern medical training [29].

Modifying the standard Learning Outcomes with such an updated curriculum could then be triangulated with Teaching \& Learning Activities and Assessment, thus coming into better pedagogical alignment. This triangulation has been described by Biggs as Constructive Alignment in educational theory [30] and will be further explored as a research framework in Part 2 of this paper.

\section{Conclusion}

Biological constructs are complex systems rooted in metaphor, however, a word in a sentence, a sentence in a paragraph, or a paragraph in a chapter cannot reflect the reality of the narrative of an entire book. Narratives are a tool we use to describe nonlinear processes unfolding, just as our anatomical nomenclature is a tool we use to understand our bodies. Human anatomy, and all biologic form, is by nature spatiotemporal structure that defies linear laws. This new proposed paradigm shifts anatomy away from reductionist fascia phobia explanations towards a wholistic model endorsed by fascial continuity.

Further, the pedagogical framework in medical education requires a congruent shift if we are to pave the way for a progressive medical profession that adapts to advances in the research on connective tissue. This shift comes in the form of adjusting curricular alignment to update the models of anatomy we have inherited without question from the era of the steam engine. This, the ubiquitous "classical model", is generally based on continuous compression elements described as discrete units without any emphasis on their kinematic interconnectedness through global cytoskeletal tension.

Tensegrity based architecture speaks of the force vectors operating within and constructing the form while reflecting elemental geometrical properties that underlie all living constructs. Our proposal rests on nested constraints: the classical model of anatomy needs updated to incorporate tensegrity, and consequently the 
pedagogical tools we use to teach and learn anatomy are also in need of an upgrade. Part I of this paper has provided the backdrop for seeing this need for connectedness and realignment of anatomy within the continuum. In Part II, we will deal in detail with tensegrity and pedagogy as part of our "Tension-spanning and tissue-sparing: methods for teaching global fascia continuity in anatomy".

\section{References}

[1]. Heylings DJ. Anatomy 1999-2000: the curriculum, who teaches it and how? Med Educ. 2002 Aug;36(8):702-10.Pubmed PMID: 12191052.

[2]. Sheikh AH, Barry DS, Gutierrez H, Cryan JF, O'Keeffe GW. Cadaveric anatomy in the future of medical education: What is the surgeons view? Anat Sci Educ. 2016 Mar-Apr;9(2):203-8.Pubmed PMID: 26213365.

[3]. Sakamoto Y, Kokudo N, Kawaguchi Y, Akita K. Clinical Anatomy of the Liver: Review of the 19th Meeting of the Japanese Research Society of Clinical Anatomy. Liver Cancer. 2017 Feb;6(2):146-160.Pubmed PMID: 28275581

[4]. Stecco A, Macchi V, Stecco C, Porzionato A, Ann Day J, Delmas V, et al. Anatomical study of myofascial continuity in the anterior region of the upper limb. J Bodyw Mov Ther. 2009 Jan;13(1):53-62.Pubmed PMID: 19118793.

[5]. Trewartha JE, Wheeler SL. Scars, adhesions and the biotensegral body. . Jan E Trewartha and Sharon, L Wheeler.2020.

[6]. Stecco C, Gagey O, Belloni A, Pozzuoli A, Porzionato A, Macchi V, et al. Anatomy of the deep fascia of the upper limb. Second part: study of innervation. Morphologie. 2007 Mar;91(292):38-43.Pubmed PMID: 17574469.

[7]. Benjamin M. The fascia of the limbs and back--a review. J Anat. 2009 Jan;214(1):1-18.Pubmed PMID: 19166469.

[8]. Tubbs RS, Sorenson EP, Sharma A, Benninger B, Norton N, Loukas M, et al. The development of a core syllabus for the teaching of head and neck anatomy to medical students. Clin Anat. 2014 Apr;27(3):321-30.

[9]. Sharkey, J. Site-Specific Fascia Tuning Pegs and Places of Perilous Passage. Myofascial Considerations in Upper Extremity Entrapment Neuropathies: A Clinical Anatomists View . Int J Anat Res 2020;8(4.2):7823-7828.

[10]. Pratt RL. Educational avenues for promoting dialog on fascia. Clin Anat. 2019 Oct;32(7):871-876.Pubmed PMID: 30951216.

[11]. Lackey-Cornelison WL, Bauler LD, Smith J. A comparison of the effectiveness of dissection and prosection on short-term anatomic knowledge retention in a reciprocal peer-teaching program. Adv Physiol Educ. 2020 Jun 1;44(2):239-246.Pubmed PMID: 32412383.

[12]. Smith CF, Finn GM, Stewart J, McHanwell S. Anatomical Society core regional anatomy syllabus for undergraduate medicine: the Delphi process. J Anat. 2016 Jan;228(1):2-14.Pubmed PMID: 26612335.

[13]. Monkhouse WS, Farrell TB. Tomorrow's doctors: today's mistakes? Clin
Anat. 1999;12(2):131-4.Pubmed PMID: 10089040.

[14]. Schleip R, Zorn A, Klingler W. Biomechanical properties of fascial tissues and their role as pain generators. J. Musculoskelet. Pain. 2010 Oct $1 ; 18(4): 393-5$

[15]. Stecco C, Tiengo C, Stecco A, Porzionato A, Macchi V, Stern R, et al. Fascia redefined: anatomical features and technical relevance in fascial flap surgery. Surg Radiol Anat. 2013 Jul;35(5):369-76.Pubmed PMID: 23266871

[16]. Casato G, Stecco C, Busin R. Role of fasciae in nonspecific low back pain. Eur. J. Transl. Myol. 2019 Aug 2;29(3): 8330.

[17]. Stecco C, Macchi V, Porzionato A, Duparc F, De Caro R. The fascia: the forgotten structure. Ital J Anat Embryol. 2011;116(3):127-38.Pubmed PMID: 22852442.

[18]. Stecco C, Stern R, Porzionato A, Macchi V, Masiero S, Stecco A, et al. Hyaluronan within fascia in the etiology of myofascial pain. Surg Radiol Anat. 2011 Dec;33(10):891-6.Pubmed PMID: 21964857.

[19]. Sharkey, J. Regarding: Update on fascial nomenclature - An additional proposal by John Sharkey MSc, Clinical Anatomist. J Bodyw Mov.2018; 23(1).

[20]. Sharkey J. Fascia Focused Manual Therapy Interventions-Proposed Treatment for Post-COVID Syndrome. Integr J Med Sci. 2021 Jan 6;8.

[21]. Sharkey J. Fascia The Universal Singularity Of Biotensegrity The Dark Matter Of Our Inner Cosmos. Int J Anat Appl Physiol. 2021 Mar 22;7(02):17984.

[22]. Stecco C, Porzionato A, Macchi V, Stecco A, Vigato E, Parenti A, et al. The expansions of the pectoral girdle muscles onto the brachial fascia: morphological aspects and spatial disposition. Cells Tissues Organs. 2008;188(3):320-9. Pubmed PMID: 18349526.

[23]. Fede C, Petrelli L, Guidolin D, Porzionato A, Pirri C, Fan C, et al. Evidence of a new hidden neural network into deep fasciae. Sci Rep. 2021 Jun 16;11(1):12623.Pubmed PMID: 34135423.

[24]. Schleip R, Gabbiani G, Wilke J, Naylor I, Hinz B, Zorn A, et al. Fascia Is Able to Actively Contract and May Thereby Influence Musculoskeletal Dynamics: A Histochemical and Mechanographic Investigation. Front Physiol. 2019 Apr 2;10:336.Pubmed PMID: 31001134.

[25]. Stecco C, Fede C, Macchi V, Porzionato A, Petrelli L, Biz C, et al. The fasciacytes: A new cell devoted to fascial gliding regulation. Clin Anat. 2018 Jul;31(5):667-676.Pubmed PMID: 29575206.

[26]. Arantes M, Arantes J, Ferreira MA. Tools and resources for neuroanatomy education: a systematic review. BMC Med. Educ. 2018 Dec;18(1):194.

[27]. Harden RM. AMEE Guide No. 21: Curriculum mapping: a tool for transparent and authentic teaching and learning. Med Teach. $2001 \mathrm{Mar} ; 23(2): 123$ 137.Pubmed PMID: 11371288.

[28]. Buja LM. Medical education today: all that glitters is not gold. BMC Med Educ. 2019 Apr 16;19(1):110.Pubmed PMID: 30991988.

[29]. Quintero GA, Vergel J, Arredondo M, Ariza MC, Gómez P, Pinzon-Barrios AM. Integrated medical curriculum: advantages and disadvantages. J. med. educ. curric. dev. 2016 Jan;3:JMECD-S18920.

[30]. Biggs J. Enhancing teaching through constructive alignment. High. Educ. 1996 Oct;32(3):347-64 